\title{
Sustained insulin secretory response in human islets co-cultured with pancreatic duct-derived epithelial cells within a rotational cell culture system
}

\author{
H. E. Murray • M. B. Paget • C. J. Bailey • R. Downing
}

Received: 20 October 2008 / Accepted: 2 December 2008 / Published online: 8 January 2009

(C) Springer-Verlag 2008

\begin{abstract}
Aims/hypothesis Loss of the trophic support provided by surrounding non-endocrine pancreatic cell populations underlies the decline in beta cell mass and insulin secretory function observed in human islets following isolation and culture. This study sought to determine whether restoration of regulatory influences mediated by ductal epithelial cells promotes sustained beta cell function in vitro.

Methods Human islets were isolated according to existing protocols. Ductal epithelial cells were harvested from the exocrine tissue remaining after islet isolation, expanded in monolayer culture and characterised using fluorescence immunocytochemistry. The two cell types were co-cultured under conventional static culture conditions or within a rotational cell culture system. The effect of co-culture on islet structural integrity, beta cell mass and insulin secretory capacity was observed for 10 days following isolation. Results Human islets maintained under conventional culture conditions exhibited a characteristic loss in structural integrity and functional viability as indicated by a diminution of glucose responsiveness. By contrast, co-culture of islets with ductal epithelial cells led to preserved islet morphology and sustained beta cell function, most evident in co-cultures held within the rotational cell culture system, which showed
\end{abstract}

H. E. Murray $(\bowtie) \cdot$ M. B. Paget $\cdot$ R. Downing

The Islet Research Laboratory,

Worcestershire Clinical Research Unit,

Worcestershire Acute Hospitals NHS Trust,

Newtown Road,

Worcester WR5 1HN, UK

e-mail: hilary.murray@worcsacute.nhs.uk

\section{J. Bailey}

Diabetes Research, School of Life and Health Sciences,

Aston University,

Birmingham, UK a significantly $(p<0.05)$ greater insulin secretory response to elevated glucose compared with control islets. Similarly, insulin/protein ratio data suggested that the presence of ductal epithelial cells is beneficial for the maintenance of beta cell mass.

Conclusions/interpretation The data indicate a supportive role for ductal epithelial cells in islet viability. Further characterisation of the regulatory influences may lead to novel strategies to improve long-term beta cell function both in vitro and following islet transplantation.

Keywords Beta cells · Ductal epithelial cells .

Extracellular matrix · Glucose responsiveness · Human islets $\cdot$ Insulin secretion $\cdot$ Rotational cell culture system

$\begin{array}{ll}\text { Abbreviations } \\ \text { CK19 } & \text { cytokeratin 19 } \\ \text { CSC } & \text { conventional static culture } \\ \text { DEC } & \text { ductal epithelial cell } \\ \text { ECM } & \text { extracellular matrix } \\ \text { GSIR } & \text { glucose stimulated insulin release } \\ \text { HARV } & \text { high aspect ratio vessel } \\ \text { IEQ } & \text { islet equivalents } \\ \text { RCCS } & \text { rotational cell culture system } \\ \text { SI } & \text { stimulation index } \\ \text { TP } & \text { theophylline }\end{array}$

\section{Introduction}

The optimal isolation and pre-culture of human islets have been shown to be pertinent to successful clinical islet transplantation $[1,2]$, yet both procedures also have detrimental effects. Disruption of the complex cytoarchitecture of 
the human islet as a consequence of isolation leads to a loss of both structural and functional integrity [3-5], and pretransplant culture is associated with a decline in beta cell mass $[6,7]$ concomitant with a marked diminution in glucose sensitivity $[8,9]$. The adverse events occurring within the islet during the early post-isolation period also narrow the 'window of opportunity' for their use in research and drug development. The design of strategies aimed at reducing or reversing isolation-induced islet injury, coupled to improved methodologies for pre-transplant culture, could help alleviate these problems.

Within the pancreas, inter-relationships between endocrine, non-endocrine and extracellular matrix (ECM) moieties have been shown to be vital for appropriate and sustained beta cell function, contributing to the complex microenvironment in which the islet resides [10]. This precisely controlled milieu is disturbed by islet processing, which results in the loss of many important physical, cellular and trophic signals required for beta cell differentiation, survival and function $[11,12]$. Notably, detachment from the ECM has been shown to leave islets prone to fragmentation [5] and susceptible to an increased frequency of apoptotic events [13, 14]. Efforts to restore the vital associations between the endocrine and ECM compartments of the pancreas in vitro have yielded promising results, with numerous studies reporting improved beta cell viability of islets cultured in the presence of soluble components of the basement membrane or on artificial matrices [7, 10, 15]. These findings suggest a direct morphological and functional benefit from the re-establishment of cell-matrix associations within the culture environment. However, there are limitations because of the nature of the biomaterials employed. While several of the more effective substrates support longterm glucose responsiveness in vitro, the use of these materials poses technical problems for the retrieval of cells for subsequent transplantation [16], and if co-transplanted, the poor rate of vascularisation within such artificial scaffolds would inevitably impede the flow of nutrients and metabolites within the islet graft, leading to central necrosis and cell death [17]. Thus, whilst effectual in vitro, the use of artificial matrices is at present incompatible with clinical islet transplantation and must await further development.

A more physiologically relevant and readily applicable strategy could involve restoration of the intrinsic influences exerted on islets by cells within the various exocrine compartments of the human pancreas. Surrounding acinar and ductal cells are considered to be the source of important islet growth and regulatory factors, and the loss of their influences following islet isolation and culture may result in disordered beta cell function $[18,19]$. In the present investigation we sought to determine whether appropriate glucose signalling and insulin secretion could be restored in culture by re-establishing cellular interactions between islets and non-endocrine components of the human pancreas. Specifically, we aimed to re-introduce the influences exerted by pancreatic ductal epithelial cells (DECs), which are considered to be a potential source of trophic factors [19], ECM components [20] and beta cell progenitors [21] thought to contribute to sustained graft survival following islet transplantation [22].

The success of such an approach depends upon the use of appropriate culture models to allow the establishment of an environment in which both islets and ductal epithelia are supported. We have previously reported on the benefits of a novel rotational cell culture system (RCCS) that prolongs the post-isolation survival of islets through improved oxygenation and maintenance of islet structural integrity [8]. We have also demonstrated that the system allows the re-association of dispersed islet cells in a physiologically relevant manner. These beneficial properties of the RCCS were therefore used to create islet-DEC co-cultures using purified cell populations derived from a well-established islet isolation procedure and sub-purification protocols, with the intention of restoring appropriate cell-mediated support to islets and enhancing long term in vitro beta cell function.

\section{Methods}

\section{Human islet isolation}

Local research ethics committee approval was obtained for the studies described. Pancreatic tissue was obtained from multi-organ donors (supplied by the UK Human Tissue Bank, De Montford University, Leicester, UK). For the purpose of this study, islets and ductal tissue were obtained from six pancreases (three male, three female; age 54.3 \pm 6.3 years). The organs were enzymatically digested under aseptic conditions and intact islets were isolated according to a previously described manual method [8, 23]. The viability of the resultant islet preparation was assessed using Trypan Blue exclusion and an islet count performed following staining with dithizone $(50 \mu \mathrm{g} / \mathrm{ml}$; SigmaAldrich, Poole, UK), prior to the re-suspension of the islets in Medium 199 containing $100 \mathrm{U} / \mathrm{ml}$ penicillin, $100 \mu \mathrm{g} / \mathrm{ml}$ streptomycin, $10 \mu \mathrm{g} / \mathrm{ml}$ amphotericin B (Sigma-Aldrich) supplemented with 10\% FCS (First Link, Birmingham, UK). Islets were maintained in suspension under conventional static culture (CSC) conditions [8] for a period of $24 \mathrm{~h}$ to acclimatise.

\section{Preparation of DEC cultures}

Following isolation, the remaining exocrine fractions were examined and those that were duct-rich but islet-depleted 
$[24,25]$ were collected and washed in sterile Hanks' balanced salt solution (Sigma-Aldrich) prior to being plated into T75 flasks (Fisher Scientific, Loughborough, UK). The exocrine cultures were maintained undisturbed for $48 \mathrm{~h}$ at $37^{\circ} \mathrm{C}$, in an atmosphere of $95 \% \mathrm{O}_{2}$ and $5 \% \mathrm{CO}_{2}$, in Dulbecco's modified Eagle's medium supplemented with $10 \%$ FBS (Sigma-Aldrich), $100 \mathrm{U} / \mathrm{ml}$ penicillin, $100 \mu \mathrm{g} / \mathrm{ml}$ streptomycin, $10 \mu \mathrm{g} / \mathrm{ml}$ amphotericin B. Adherent tissue remaining at the time of the first medium change was allowed to expand further to form an $80 \%$ confluent monolayer over the following 48-72 $\mathrm{h}$.

\section{Immunocytochemistry}

Levels of cytoskeletal and cell markers within the exocrinederived monolayers were determined using fluorescence immunocytochemistry. Monolayers were allowed to reach $80 \%$ confluence and fixed with $4 \%$ (wt/vol.) paraformaldehyde for $30 \mathrm{~min}$ at room temperature. Antigen-retrieval $(0.3 \%$ [vol./vol.] Triton X-100) and blocking ( $\%$ [wt/vol.] Roche blocking buffer) was followed by incubation with the primary antibodies anti-human cytokeratin 19 (CK19), anti-human vimentin (1:100 dilution; Dako, Ely, UK) and anti-human insulin (1:10 dilution; AbD Serotec, Oxford, UK) for $1 \mathrm{~h}$ at room temperature and overnight at $4^{\circ} \mathrm{C}$. Secondary antibody (1:100 dilution; goat anti-mouse IgGFITC; Cambridge Biosciences, Cambridge, UK) was applied for $3 \mathrm{~h}$ at room temperature before image analysis using a Zeiss Axioskop 40 fluorescence microscope equipped with an AxioCam MRc colour camera and incorporating Axiovision imaging software (Carl Zeiss, Welwyn Garden City, UK). Controls involved omission of the relevant primary antibody.

\section{Co-culture conditions}

Islets were maintained in suspension either under CSC conditions in $90 \mathrm{~mm}$ culture plates (NHS Logistics, Alfreton, UK) or in the RCCS in high aspect ratio vessels (HARVs; Cellon, Bereldange, Luxembourg), as previously described [8]. To ensure cultures were plated at equal density, islets were counted, sized and converted into standard islet equivalents (IEQ) with a diameter of 150 $\mu \mathrm{m}$ [4]. For both conditions, islets were plated at a density of $500-1,000 \mathrm{IEQ} / \mathrm{ml}$ and cultures were maintained at $30^{\circ} \mathrm{C}$ in a humidified atmosphere of $95 \% \mathrm{O}_{2}, 5 \% \mathrm{CO}_{2}$ for the duration of the investigation. After $72 \mathrm{~h}, 80 \%$ confluent CK19-positive DEC monolayers were disrupted by mild enzymatic digestion $(0.025 \%$ [wt/vol.] trypsin-EDTA in PBS; Sigma-Aldrich), and the resulting DEC suspension was introduced to the islet cultures (CSC and RCCS) at a density of $1 \times 10^{4}$ cells $/ \mathrm{ml}$. Control cultures (CSC and RCCS) were maintained in the absence of DECs.
Functional assessment

Static challenge studies Cultures of islets or co-cultures consisting of islets and DECs maintained either under CSC or within the RCCS, as described above, were assessed for preserved glucose responsiveness over a period of 10 days post isolation. The effect of culture condition on islet function was determined by measuring insulin release in response to a glucose challenge employing static incubation methods. Insulin release under basal conditions $(1.67 \mathrm{mmol} / \mathrm{l}$ glucose in modified HEPES-buffered Hanks' balanced salt solution containing $0.2 \%$ [wt/vol.] $\mathrm{BSA}, \mathrm{pH} 7.4$, at $37^{\circ} \mathrm{C}$ ) and after stimulation with high glucose $(16.7 \mathrm{mmol} / \mathrm{l})$ or a combination of $16.7 \mathrm{mmol} / 1$ glucose and $10 \mathrm{mmol} / \mathrm{l}$ theophylline (TP) was determined according to previously described methods $[8,23]$. The insulin secretory capacity demonstrated by islets maintained under CSC conditions was compared with that shown by islets held within the RCCS and islets in co-culture with DECs under the two culture conditions. Their response to glucose stimulation was quantified by measurement of insulin in the incubation medium. Nutrient challenge studies were performed on the islets at $24 \mathrm{~h}$ post isolation, $72 \mathrm{~h}$ after the initiation of the cocultures (day 7 post isolation) and after an extended period of co-culture (day 10 post isolation).

Insulin and protein content In limited studies we assessed the insulin:total protein ratios of the islet and islet-DEC cultures. For this purpose, islets and/or islets-DECs were harvested at day 4 , day 7 and day 10 post isolation. Aliquots containing 200 IEQs were washed three times in PBS ( $\mathrm{pH} 7.4$; Sigma-Aldrich) before cell lysis in a high-salt buffer $(2.15 \mathrm{~mol} / 1 \mathrm{NaCl}, 0.1 \mathrm{~mol} / 1$ $\mathrm{NaH}_{2} \mathrm{PO}_{4}, 0.04 \mathrm{~mol} / 1 \mathrm{Na}_{2} \mathrm{HPO}_{4} 1 \mathrm{mmol} / \mathrm{l}$ EDTA), which was assisted by sonication. Following centrifugation at $400 \mathrm{~g}$ for $3 \mathrm{~min}$, the supernatant fraction was collected and stored at $-80^{\circ} \mathrm{C}$ prior to insulin and protein determination. For completeness, samples of tissue from the initial exocrine material (pre-plating) and from the monolayers after $72 \mathrm{~h}$ of expansion culture were processed in a similar manner.

Insulin and protein analysis Human insulin measurements were performed using a commercially available ELISA (Mercodia kit supplied by Diagenics, Milton Keynes, UK). The assay exhibits limited $(<0.01 \%$ [wt/wt] cross-reactivity with proinsulin. Insulin secretion under stimulated conditions was calculated as the fold increase over basal release (i.e. the stimulation index [SI]), as previously described [8]. Protein content was ascertained by use of the Bradford colorimetric assay [26]. 


\section{Statistical analysis}

Statistical differences between culture conditions and the various secretagogues were assessed by one-way ANOVA using islet preparations maintained under CSC conditions as the control group. A $p$ value of less than 0.05 was considered to be statistically significant.

\section{Results}

Morphological and immunocytochemical assessment of islet and exocrine fractions post isolation

The pancreas digestion method adopted for the present study allowed the harvest of predominantly structurally intact human islets that were well cleaved from the surrounding exocrine tissue (Fig. 1a). Post purification, islet sizes ranged from $100-500 \mu \mathrm{m}$ in diameter; larger $(>700 \mu \mathrm{m})$ islets were occasionally observed. Purity ranged from $70-85 \%$ immediately after isolation and mostly increased following the initial $24 \mathrm{~h}$ culture period.

The islet-depleted exocrine fraction was washed and plated for culture at high density in T75 flasks as previously described $[21,24]$. The vast majority $(>80 \%)$ of the plated material remained non-adherent at $48 \mathrm{~h}$ and was discarded in the first medium change. The cells emerging from the adhered tissue aggregates were mainly flattened epitheliallike cells, which appeared to form a homogeneous population (Fig. 1b, c). Subsequent immunocytochemical analysis confirmed that approximately $95 \%$ of the cells within the monolayer were positive for the duct epithelial cell marker CK19 (Fig. 1d). During this initial expansion phase there was only minimal $(<5 \%)$ staining for the fibroblast marker vimentin (Fig. 1e). A faint fluorescence signal was sometimes observed for insulin, but this was not consistently seen (Fig. 1f). The CK19-positive cells demonstrated a high proliferative capacity, reaching $80 \%$ confluence 4-5 days following isolation.

Islet morphology in RCCS and co-culture with DECs: comparison with conventional culture conditions

Isolated human islets maintained in the absence of DECs under CSC conditions demonstrated a characteristic gradual loss of structural integrity during the period of investigation, leading to fragmentation by day 10 after isolation (Fig. 2a). By contrast, islets held in the RCCS for the same period of time displayed preserved morphology (Fig. 2b). Co-culture with DECs markedly reduced fragmentation of human islets under CSC conditions, with the endocrine cells often associated with closely interspersed non-endocrine cells (Fig. 2c). Islets and DECs in co-culture within the RCCS appeared to form aggregates with a preserved islet-like morphology (Fig. 2d).

\section{Functional assessment}

Islet function 24 h post isolation Glucose challenge experiments performed after the initial $24 \mathrm{~h}$ under CSC conditions demonstrated that human islets retained normal glucose sensitivity for this period following isolation, with exposure to high $(16.7 \mathrm{mmol} / \mathrm{l})$ glucose producing a mean SI of $2.48 \pm 0.27$ compared with basal release. Insulin secretion in the presence of $16.7 \mathrm{mmol} / \mathrm{l}$ glucose and $10 \mathrm{mmol} / \mathrm{l}$ theophylline elicited a mean SI of $3.21 \pm 0.29$ at the same time point (Fig. 3).
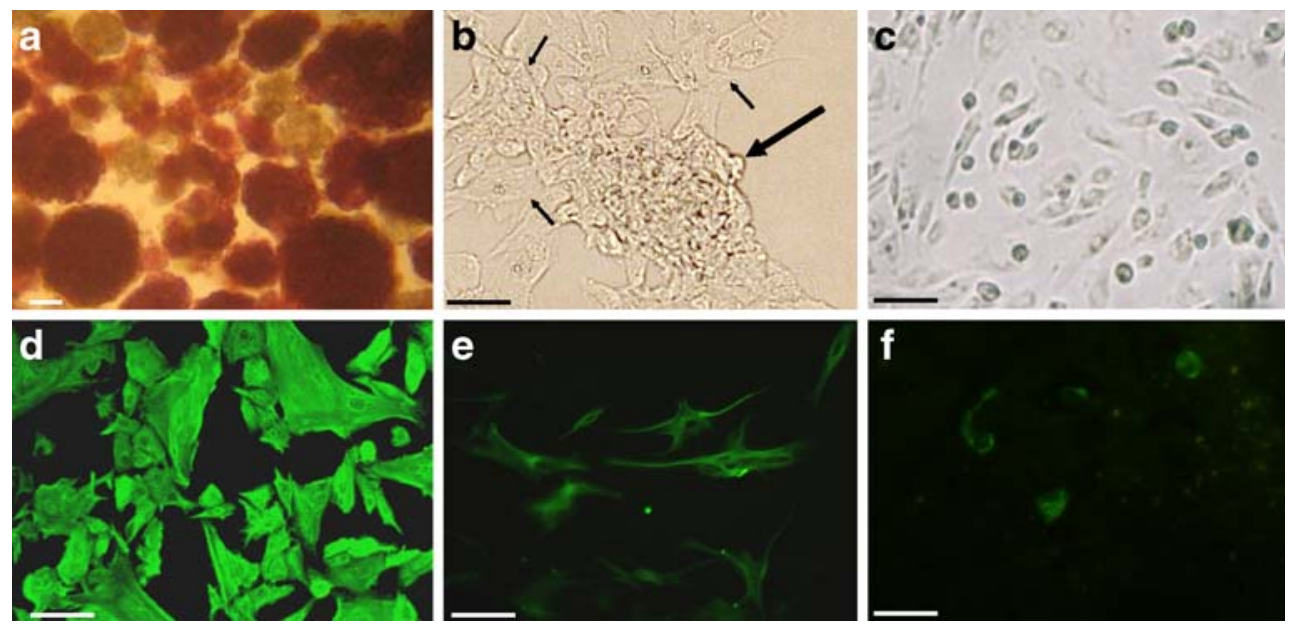

Fig. 1 a Isolated human islets stained with dithizone and viewed at $24 \mathrm{~h}$ post isolation. b Outgrowth cultures from the exocrine fraction viewed under a phase contrast microscope, showing the initial adherent tissue (large arrow), with flattened epithelial cells emerging (small arrows). Monolayers of DECs visualised by phase contrast

microscopy (c) and following immunocytochemical localisation of CK19 (d). During expansion the monolayers showed limited, discrete vimentin staining (e), and faint positive staining for insulin was observed in certain cultures but was not consistently seen in all the preparations processed (f). Scale bar $=100 \mu \mathrm{m}$ 


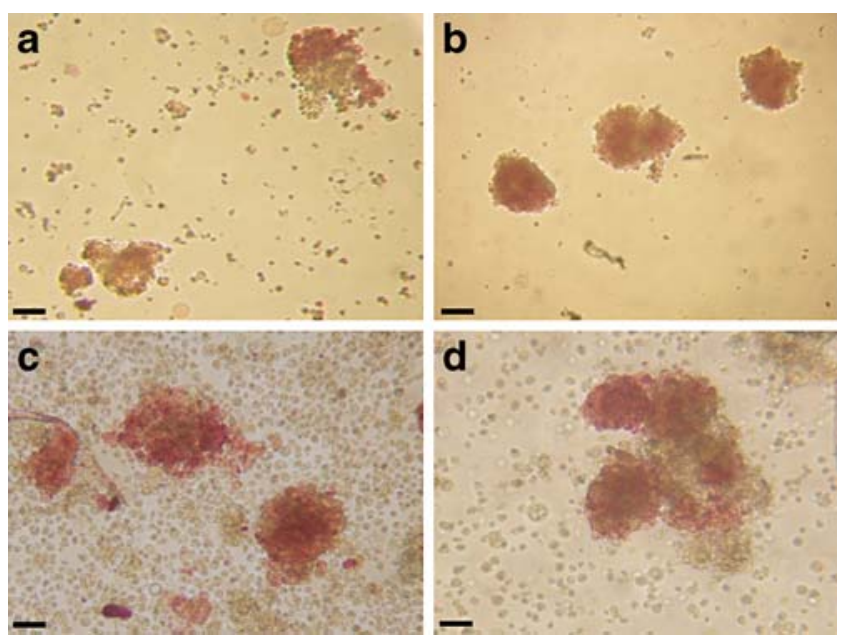

Fig. 2 Morphological characteristics of human islets maintained under different culture conditions for 10 days post isolation. Human islets maintained under CSC conditions (a) and within the RCCS (b), and cocultures of human islets and DECs maintained under CSC conditions (c) and within the RCCS (d). Scale bars: $\mathbf{a}, \mathbf{b}=50 \mu \mathrm{m} ; \mathbf{c}, \mathbf{d}=100 \mu \mathrm{m}$

Effect of culture condition on islet function at 7 days post isolation Consistent with our previous results [8], control islets i.e. those maintained alone under CSC conditions, demonstrated a marked attenuation in glucose-stimulated insulin release (GSIR) in response to long-term culture. By contrast, co-cultures of islets and DECs produced a slight, yet significant, insulin secretory response (SI $1.33 \pm 0.11$ and $1.94 \pm 0.2$ for high glucose and high glucose + TP, respectively, $p<0.05$ vs basal release) at 7 days post isolation. Maintenance of islets within the RCCS supported beta cell function, with glucose stimulation inducing a significant insulin secretory response in these cells compared with control islets (SI $1.34 \pm 0.093$ and $2.05 \pm 0.13$ for

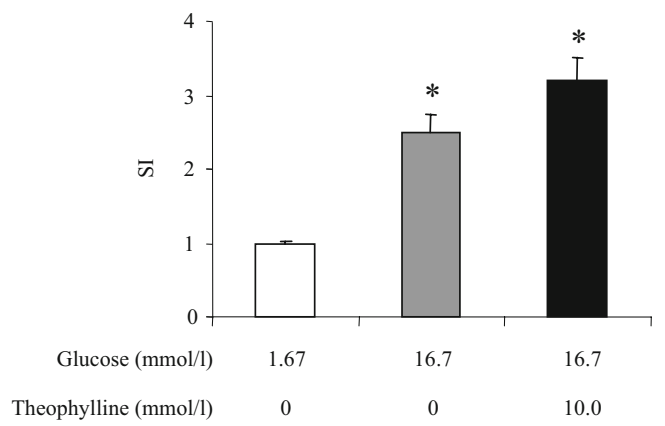

Fig. 3 Insulin secretion from isolated human islets in response to nutrient stimulation during static challenge experiments performed $24 \mathrm{~h}$ post isolation. Islets were maintained under CSC conditions prior to assessment of secretory function. Insulin release was measured in response to $1.67 \mathrm{mmol} / 1$ glucose (basal release), $16.7 \mathrm{mmol} / \mathrm{l}$ glucose and $16.7 \mathrm{mmol} / 1$ glucose plus $10 \mathrm{mmol} / 1$ theophylline. Results are expressed as the mean \pm SEM fold increase in insulin release in response to nutrient stimulation relative to release under basal conditions; $n=6$ for each secretagogue tested. The absolute mean value for insulin secretion under basal conditions was $189.7 \pm$ 14.4 pmol $[20 \text { islets }]^{-1} \mathrm{~h}^{-1}$. ${ }^{*} p<0.05$ vs basal conditions high glucose and high glucose $+\mathrm{TP}$, respectively, $p<0.05$ ), and co-culture of islets and DECs within the RCCS also promoted a sustained GSIR at this time point (SI 1.45 \pm 0.09 and $1.87 \pm 0.072$ for high glucose and high glucose $+\mathrm{TP}$, respectively, $p<0.05$ vs basal insulin release) (Fig. 4a).

Effect of extended culture on islet function-10 days post isolation We considered the possibility that the important cell-cell interactions and/or cell-mediated influences within the co-cultures may require a longer period to become reestablished. In the present study we therefore extended the period of co-culture to 10 days post isolation and determined glucose responsiveness at this time point (Fig. 4b). Control islets continued to be adversely affected by maintenance under CSC conditions, with negligible insulin secretion observed in the presence of elevated glucose, although their response to $16.7 \mathrm{mmol} / 1$ glucose in combination with $10 \mathrm{mmol} / \mathrm{l}$ theophylline remained at a level comparable to that observed at day 7. A similar secretory profile was

\section{a}

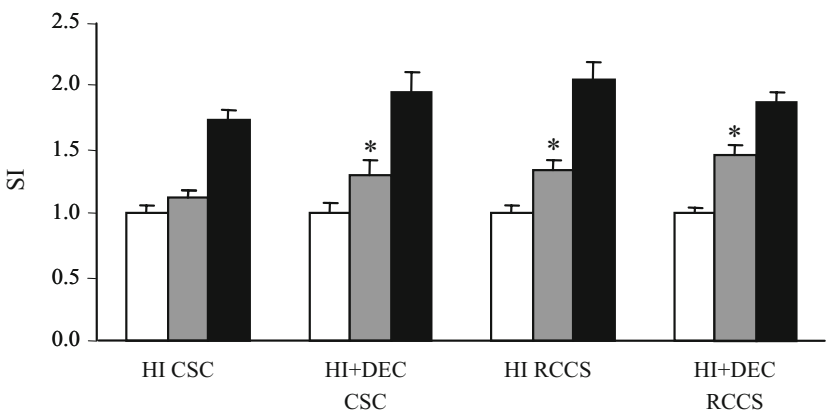

b

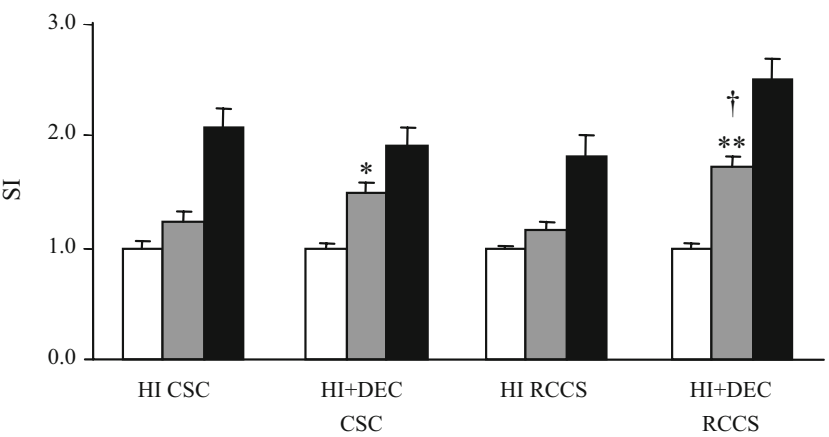

Fig. 4 Insulin secretion from isolated human islets (HI) and human islet-DEC co-cultures (HI+DEC) in response to nutrient stimulation during static challenge experiments performed at day 7 (a) and day 10 (b) post isolation. Islets or islet-DEC co-cultures were maintained either under CSC conditions or within the RCCS prior to assessment of secretory function. Insulin release was measured in response to $1.67 \mathrm{mmol} / 1$ glucose (white bars, basal release), $16.7 \mathrm{mmol} / \mathrm{l}$ glucose (grey bars) and $16.7 \mathrm{mmol} / 1$ glucose plus $10 \mathrm{mmol} / 1$ theophylline (black bars). Results are expressed as the mean \pm SEM fold increase in insulin release in response to nutrient stimulation relative to release under basal conditions; $n=6$ for each secretagogue tested. ${ }^{*} p<0.05$, ${ }^{* *} p<0.01$ vs basal release; ${ }^{\dagger} p<0.05$ vs control islets on day 10 
observed in the islets held within the RCCS at this time point. However, whilst the beneficial influence of the RCCS per se was lost by day 10, the impact of DEC coculture on human islets persisted. Thus, islet-DEC cocultures held under CSC conditions demonstrated continued glucose-induced insulin release, and this was further enhanced in the presence of the potentiator (SI $1.48 \pm 0.1$ and $1.91 \pm 0.15$ for high glucose and high glucose $+\mathrm{TP}$, respectively, $p<0.05$ ), while the greatest insulin secretory response was exhibited by the islets-DECs maintained within the RCCS (SI $1.71 \pm 0.27$ and $2.51 \pm 0.17$ for high glucose and high glucose + TP, respectively, $p<0.01$ ) (Fig. 4b).

Insulin and protein content The heterotypic nature of the islet-DEC co-cultures precluded the use of conventional insulin/protein ratio analysis to directly compare insulin synthesis and secretory capacity under the differing culture conditions. Nevertheless, we sought to ascertain, in a limited study, the effectiveness of DEC co-culture in preserving islet cell mass during extended periods following isolation. In line with the secretion data, these results suggest that the insulin content of the islets maintained under CSC conditions declined markedly during the period of investigation, as indicated by the fall in the insulin/protein ratio (Table 1), while those held within the RCCS exhibited sustained insulin content during the first 7 days post isolation but suffered a similar loss thereafter. In the case of the co-cultures, the insulin/protein ratio is much smaller because of the additional protein provided by the purified DEC population. Nevertheless, there is evidence of sustained insulin content between day 7 and day 10, both in the islets held in co-culture under CSC conditions and within the RCCS. The insulin/protein ratio of the unrefined exocrine digest suggests the presence of endocrine tissue, but this declined rapidly during expansion of the ductal cell monolayer, resulting in a ratio approximately $0.1 \%$ of that seen in the intact islets at the same time point (day 4) post isolation (Table 1).

\section{Discussion}

Disassociation from important non-endocrine cellular influences is considered to underlie the loss of both islet cell mass and function immediately following isolation and during the early post-transplant period. In the present study we hypothesised that attempts to re-establish some of these critical cell-cell interactions may serve to reverse isolationinduced islet injury and thus support in vitro beta cell viability. The data obtained from the present investigation suggest that the re-introduction of pancreatic ductal epithelial cells improves human islet function, and that the rotational cell culture system provides an appropriate environment for the restoration of these important cell-cell interactions.

The presence of DECs had a beneficial effect on islet function even under static culture conditions, where beta cells retained the ability to respond to elevated glucose when control islets had lost sensitivity. While there is little opportunity for complex cellular interaction between islets and DECs within this non-dynamic culture system, the presence of large numbers of ductal cells may be sufficient to promote continued beta cell function. Although the RCCS provided a degree of support to the islets during the initial stages of the investigation, most likely by enabling preservation of islet structural integrity [8], their separation from important non-endocrine influences reduced the longterm advantage. The combination of these two culture variables yielded the greatest response, with the islet-DEC aggregates held within the RCCS showing both preserved morphology and functional integrity for up to 10 days post isolation. It is likely that the simulated micro-gravity environment created within the RCCS [27] permits a greater degree of physiologically appropriate cell-cell contact and signalling, and as the cells are in a constant state of free-fall, the opportunity for islet exposure to soluble duct-derived trophic factors is enhanced. This isletprotecting effect of the DECs is also reflected in the insulin

Table 1 Insulin/protein ratios for the unrefined exocrine tissue, expanded monolayer and islets held in isolation or in combination with DECs under CSC conditions or within the RCCS

\begin{tabular}{|c|c|c|c|c|}
\hline \multirow[t]{2}{*}{ Sample } & \multicolumn{4}{|c|}{ Time post isolation (days) } \\
\hline & 0 & 4 & 7 & 10 \\
\hline Unrefined exocrine tissue ( $1 \mathrm{ml}$ of pellet) & $0.053 \pm 0.017$ & & & \\
\hline Expanded monolayer $\left(1 \times 10^{4}\right.$ cells $)$ & & $0.00142 \pm 0.0006$ & & \\
\hline Human islets (200 IEQs in CSC) & & $1.21 \pm 0.08$ & $0.48 \pm 0.1 *$ & $0.35 \pm 0.05^{*}$ \\
\hline Human islets (200 IEQs in RCCS) & & $1.07 \pm 0.14$ & $1.44 \pm 0.16$ & $0.42 \pm 0.11 *$ \\
\hline Human islets + DECs (200 IEQs in CSC) & & & $0.06 \pm 0.01$ & $0.09 \pm 0.003$ \\
\hline Human islets + DECs (200 IEQs in RCCS) & & & $0.034 \pm 0.005$ & $0.036 \pm 0.007$ \\
\hline
\end{tabular}

Values represent the mean ratio of total insulin $(\mathrm{ng})$ to total protein $(\mu \mathrm{g})$ at the time point tested. $n=3$ independent determinations. The lower ratios in the co-cultures represent the larger protein content of the DECs. ${ }^{*} p<0.05$ for insulin/protein ratio at day 7 or 10 compared with day 4 
content analysis. Consistent with the insulin secretion data, the insulin/protein ratio demonstrates that conventional culture methods alone are unable to prevent a loss in beta cell mass and that islets held within the RCCS in the absence of non-islet cell-mediated support eventually succumb to a similar fate. By contrast, the presence of DECs under either culture condition allows the intracellular insulin content to be sustained for extended periods post isolation.

The population of ductal cells used in the present investigation has previously been described [21, 24, 28]. Thus, the expansion of cells derived from the islet-depleted exocrine fraction, which is usually discarded following isolation, has been shown to give rise to a near homogeneous population of CK19-positive epithelial cells, with minimal fibroblast contamination during the initial phase of culture $[21,25]$. Although it is not possible to completely eliminate endocrine components from the initial plated material, previous studies have shown that such culture conditions are not conducive either to the adherence or prolonged survival of native islet cells [25] and that any endocrine cells that do exist become de-differentiated within 3-4 days of monolayer culture [24, 29]. In our study we found that over $90 \%$ of the cells derived from the outgrowth cultures were positive for CK19 at the time of the initiation of the islet-DEC co-cultures. Insulin-positive cells were inconsistently observed in the exocrine fractions used, and when found, made up less than $1 \%$ of the confluent monolayer. Furthermore, analysis of insulin content suggests that the monolayers could be responsible for only a minute amount of the total insulin within the cocultures. It is therefore unlikely that the improved insulin secretory response seen in the islet-DEC co-cultures during the 10 day period of the investigation was solely due to a greater initial mass of islet material.

This population of cells has been used as a precursor in the in vitro engineering of new insulin-secreting cells, with various methods being devised for their expansion and differentiation to an endocrine phenotype. Most involve the use of serum-free, growth factor-supplemented media and the reorganisation of the cells into three-dimensional, matrix-supported structures $[21,24,30]$. It was not the aim of the present study to encourage the production of new beta cells, and no attempt was made to alter the phenotype of the duct epithelial cells prior to the inoculation of the islet cultures. Also, to our knowledge, there are no data to support the spontaneous, ex vivo differentiation of exocrine cells to an endocrine phenotype when placed either in contact with native islet cells or within the RCCS. However, we observed no increase in insulin production within the DECs per se when they were held alone either under conventional static culture conditions or within the RCCS (data not shown). Thus, we propose that as our co- culture model was not designed to promote beta cell neogenesis arising from ductal precursors, this was not a major contributing factor underlying the improved function of the islets during extended periods of isolation.

The precise mechanism by which the DECs exert beta cell protective influences is the subject of ongoing studies, but the literature provides us with a rationale for the present findings. The role played by the DEC in our study is akin to the regulatory one it performs in the normal pancreas, where the relationship between the ductal and endocrine pancreatic components begins in embryonic development with the budding of the primordial ductal epithelium and the emergence of primitive islets [31, 32]. The phenotypic maturation and differentiation of these cellular aggregates requires signals supplied by adjacent cells, which take the form of soluble, trophic factors released in a paracrine fashion [33, 34]. This cellular inter-relationship is conserved in adulthood; maintenance of beta cell mass and remodelling occurs due to constant, yet limited, islet neogenesis [35], again under the influence of soluble factors derived from the ductal epithelium [34, 36, 37]. Although, to date, most of the supporting evidence for this concept has been derived from animal (mainly rodent) studies, the results of the present investigation suggest that similar regulatory and/or trophic influences, exerted by the ductal epithelia, may be crucial for appropriate and sustained human beta cell function. Soluble mediators such as IGF-1 and -2 and the epidermal growth factor (EGF) family have been implicated in beta cell survival and replication [38-41], and ductal epithelial cells may provide an additional source of these regulatory hormones in the post-isolation environment [41]. Additionally, components of the ECM are vital for appropriate pancreatic development, and several integrin receptors and their associated ligands, including laminin, fibronectin and collagen I, are produced in ductal cells [41-43]. Whether the actions of one or several of these factors underlie the improved beta cell function in our co-culture models will thus form the basis of future research.

The results of recent clinical trials in islet transplantation suggest that improved graft survival correlates, to an extent, with the presence of unprocessed exocrine material inadvertently co-transplanted with human islet cells [22]. This material may provide a pool of progenitor cells with the capacity to differentiate to insulin-secreting cells and thus increase the functional beta cell mass. It is also possible that a component of the exocrine fraction additionally serves as a source of regulatory factors that the isolated islet requires for sustained and appropriate function. Although re-introducing unrefined pancreatic tissue to the purified islet pool is not expedient, we envisage that, on the basis of this study, it may be possible to identify, further purify and expand a subpopulation of pancreatic cells that are able to provide trophic 
support to existing beta cells. We propose that these cells could serve as cellular chaperones to isolated human islets in culture, helping to reverse isolation-induced islet injury and extend the period of time over which islets could be used for biomedical and pharmaceutical research. Furthermore, in time, clinically relevant constructs comprising beta cells and DECs may be designed in which discrete yet vital cellular interactions are preserved to ensure longer term graft survival.

Acknowledgements This work was funded in part by a Diabetes UK Small Grant (No. RD04/0002834). We are grateful to The Eveson Charitable Trust, The Rowlands Trust, The South Warwickshire Diabetes UK Voluntary Group and Worcestershire Acute Hospitals NHS Trust R\&D for generous financial support.

Duality of interest The authors declare that there is no duality of interest associated with this manuscript.

\section{References}

1. Warnock GL, Meloche RM, Thompson D et al (2005) Improved human pancreatic islet isolation for a prospective cohort study of islet transplantation vs best medical therapy in type 1 diabetes mellitus. Arch Surg 140:735-744

2. Froud T, Ricordi C, Baidal DA et al (2005) Islet transplantation in type 1 diabetes mellitus using cultured islets and steroid-free immunosuppression: Miami experience. Am J Transplant 5:2037-2046

3. Brandhorst D, Brandhorst H, Hering BJ, Federlin K, Bretzel RG (1995) Islet isolation from the pancreas of large mammals and humans: 10 years of experience. Exp Clin Endocrinol Diabetes 103(Suppl 2):3-14

4. Ricordi C, Gray DW, Hering BJ et al (1990) Islet isolation assessment in man and large animals. Acta Diabetol Lat 27:185-195

5. Rosenberg L, Wang R, Paraskevas S, Maysinger D (1999) Structural and functional changes resulting from islet isolation lead to islet cell death. Surgery 126:393-398

6. Holmes MA, Clayton HA, Chadwick DR, Bell PR, London NJ, James RF (1995) Functional studies of rat, porcine, and human pancreatic islets cultured in ten commercially available media. Transplantation 60:854-860

7. Beattie GM, Leibowitz G, Lopez AD, Levine F, Hayek A (2000) Protection from cell death in cultured human fetal pancreatic cells. Cell Transplant 9:431-438

8. Murray HE, Paget MB, Downing R (2005) Preservation of glucose responsiveness in human islets maintained in a rotational cell culture system. Mol Cell Endocrinol 238:39-49

9. Brandhorst H, Brandhorst D, Lau D, Hering BJ, Federlin K, Bretzel RG (1999) Glucose sensitivity of porcine and human islets in vitro. J Mol Med 77:90-92

10. Bosco D, Meda P, Halban PA, Rouiller DG (2000) Importance of cell-matrix interactions in rat islet beta-cell secretion in vitro: role of $\alpha 6 \beta 1$ integrin. Diabetes 49:233-243

11. Nagata NA, Inoue K, Tabata Y (2002) Co-culture of extracellular matrix suppresses the cell death of rat pancreatic islets. J Biomater Sci Polym Ed 13:579-590

12. Wang RN, Rosenberg L (1999) Maintenance of beta-cell function and survival following islet isolation requires re- establishment of the islet-matrix relationship. $\mathrm{J}$ Endocrinol 163:181-190

13. Federici M, Hribal M, Perego L et al (2001) High glucose causes apoptosis in cultured human pancreatic islets of Langerhans: a potential role for regulation of specific $\mathrm{Bcl}$ family genes toward an apoptotic cell death program. Diabetes 50:1290-1301

14. Ris F, Hammar E, Bosco D et al (2002) Impact of integrin-matrix matching and inhibition of apoptosis on the survival of purified human beta-cells in vitro. Diabetologia 45:841-850

15. Brendel MD, Kong SS, Alejandro R, Mintz DH (1994) Improved functional survival of human islets of Langerhans in threedimensional matrix culture. Cell Transplant 3:427-435

16. Beattie GM, Montgomery AM, Lopez AD et al (2002) A novel approach to increase human islet cell mass while preserving betacell function. Diabetes 51:3435-3439

17. Ko HC, Milthorpe BK, McFarland CD (2007) Engineering thick tissues - the vascularisation problem. Eur Cell Mater 14:1-18

18. Bertelli E, Bendayan M (2005) Association between endocrine pancreas and ductal system. More than an epiphenomenon of endocrine differentiation and development? J Histochem Cytochem 53:1071-1086

19. Ilieva A, Yuan S, Wang RN, Agapitos D, Hill DJ, Rosenberg L (1999) Pancreatic islet cell survival following islet isolation: the role of cellular interactions in the pancreas. J Endocrinol 161:357-364

20. Jiang FX, Naselli G, Harrison LC (2002) Distinct distribution of laminin and its integrin receptors in the pancreas. J Histochem Cytochem 50:1625-1632

21. Bonner-Weir S, Toschi E, Inada A et al (2004) The pancreatic ductal epithelium serves as a potential pool of progenitor cells. Pediatr Diabetes 5(Suppl 2):16-22

22. Street CN, Lakey JR, Shapiro AM et al (2004) Islet graft assessment in the Edmonton Protocol: implications for predicting long-term clinical outcome. Diabetes 53:3107-3114

23. Paget M, Murray H, Bailey CJ, Downing R (2007) Human islet isolation: semi-automated and manual methods. Diab Vasc Dis Res 4:7-12

24. Gao R, Ustinov J, Pulkkinen MA, Lundin K, Korsgren O, Otonkoski T (2003) Characterization of endocrine progenitor cells and critical factors for their differentiation in human adult pancreatic cell culture. Diabetes 52:2007-2015

25. Bonner-Weir S, Taneja M, Weir GC et al (2000) In vitro cultivation of human islets from expanded ductal tissue. Proc Natl Acad Sci USA 97:7999-8004

26. Bradford MM (1976) A rapid and sensitive method for the quantitation of microgram quantities of protein utilizing the principle of protein-dye binding. Anal Biochem 72:248-254

27. Unsworth BR, Lelkes PI (1998) Growing tissues in microgravity. Nat Med 4:901-907

28. Yatoh S, Dodge R, Akashi T et al (2007) Differentiation of affinity-purified human pancreatic duct cells to beta-cells. Diabetes 56:1802-1809

29. Gao R, Ustinov J, Korsgren O, Otonkoski T (2005) In vitro neogenesis of human islets reflects the plasticity of differentiated human pancreatic cells. Diabetologia 48:2296-2304

30. Hao E, Tyrberg B, Itkin-Ansari P et al (2006) Beta-cell differentiation from nonendocrine epithelial cells of the adult human pancreas. Nat Med 12:310-316

31. Rutter WJ (1980) The development of the endocrine and exocrine pancreas. Monogr Pathol 21:30-38

32. Slack JM (1995) Developmental biology of the pancreas. Development 121:1569-1580

33. Scharfmann R, Czernichow P (1996) Differentiation and growth of pancreatic beta cells. Diabetes Metab 22:223-228 
34. Vinik A, Pittenger G, Rafaeloff R, Rosenberg L (1993) Factors controlling pancreatic islet neogenesis. Tumour Biol 14:184-200

35. Bonner-Weir S, Baxter LA, Schuppin GT, Smith FE (1993) A second pathway for regeneration of adult exocrine and endocrine pancreas. A possible recapitulation of embryonic development. Diabetes 42:1715-1720

36. Rosenberg L, Vinik AI (1992) Trophic stimulation of the ductularislet cell axis: a new approach to the treatment of diabetes. Adv Exp Med Biol 321:95-104

37. Metrakos P, Yuan S, Agapitos D, Rosenberg L (1993) Intercellular communication and maintenance of islet cell mass-implications for islet transplantation. Surgery 114: 423-427

38. Adams GA, Wang X, Lee LK, Piercy CE, Alfrey EJ, Dafoe DC (1994) Insulin-like growth factor-I promotes successful fetal pancreas transplantation in the intramuscular site. Surgery 116:751-755
39. Dheen ST, Rajkumar K, Murphy LJ (1997) Islet cell proliferation and apoptosis in insulin-like growth factor binding protein-1 in transgenic mice. J Endocrinol 155:551-558

40. Robertson K, Lu Y, de Jesus K et al (2008) A general and islet cell-enriched overexpression of IGF-I results in normal islet cell growth, hypoglycemia, and significant resistance to experimental diabetes. Am J Physiol Endocrinol Metab 294:E928-E938

41. Jiang FX, Harrison LC (2005) Laminin-1 and epidermal growth factor family members co-stimulate fetal pancreas cell proliferation and colony formation. Differentiation 73:45-49

42. Jiang FX, Cram DS, DeAizpurua HJ, Harrison LC (1999) Laminin-1 promotes differentiation of fetal mouse pancreatic beta-cells. Diabetes 48:722-730

43. Cirulli V, Beattie GM, Klier G et al (2000) Expression and function of $\alpha_{\mathrm{v}} \beta_{3}$ and $\alpha_{\mathrm{v}} \beta_{5}$ integrins in the developing pancreas: roles in the adhesion and migration of putative endocrine progenitor cells. J Cell Biol 150:1445-1460 